\title{
New Media and Digital Surveillance Reflections
}

\author{
Yeniceler i. ${ }^{1}$ \\ Ilgın H. Ö. ${ }^{2}$
}

${ }^{1}$ Irrem YENICELER, İstanbul Aydın University, (Turkey)
e-mail: iremyeniceler@aydin.edu.tr
${ }^{2}$ Hicran Özlem ILGIN, Çanakkale Onsekiz Mart University, (Turkey)
e-mail: hicranilgin@comu.edu.tr

Abstract

The self-renewing structure of the technology has enabled various transformations to change the existing order. This new technological structure, based on the digitalization of the individual and the society has created differences in the structure. A number of new surveillance practices have emerged in order to provide control in the digital society and to prevent possible problems. In the light of literature review, the results of the digital developments as a result of the rapid changes in human life are examined. In the study, a group of 10 subjects, aged between 18 and 23 years, focused on a group of seven subjects prepared with the data obtained from literature reviews. The questions asked in focus group work have been prepared by compiling the data on new media applications in social, economic and state dimensions. According to the results of the analysis obtained with the data obtained from the study, it was recorded that the focus group participants expressed their beliefs about the state, the economic and the social dimension of the surveillance and that even the developments were facilitated. In this context, it is seen that the criticism of the new media technologies and the new media users' satisfaction with the concept of oversight have an inverse proportion.

Keywords: Digital Surveillance, Digital Economy, Virtual Identity, New Media.

\section{Introduction}

The global environment brought by today's world has enabled the transactions to be transformed accordingly. This new environment has made its impact felt in many fields such as economy, law and communication and has been the initiator of a transformation. This global world has become like a village that McLuhan depicts, a place where people can easily achieve everything. This platform of convenience has also enabled individuals to be followed, and individuals have left behind each of their activities in this global environment as a trace. New forms of technology allow power to be retained while at the same time realizing different individual configurations on this power axis. Today, in any case, the identity is always online (Cover, 2016: 5). The situation with the new media becomes clear at this point. The institutions that take the most place in the lives of the people we will define as state, society and economy have made new transformations with the new media in order to protect their power and maintain their stability. In addition to these new transformations, new practices, new applications have been introduced and while the lives of users seem to be easier, the gates of making them live in a different world have been opened. These new control mechanisms have also brought the monitoring of individuals to a digital media, and individuals with digital identities have entered into a digital surveillance. From the point of view of the world with the new media, the individual becomes followable, recordable and measurable, in other words, they become observable and society in the context of the individual gains a new quality. While this gain can be transformed into an advantage for economic and ideological forces, there are ongoing discussions and investigations on whether this gain is a surveillance and disadvantage for the individual / society. In the light of this study, it is aimed to reveal the reflections of digital development with new media technologies on individual / community life. In this context, the evaluations will be carried out with a focus group that will be formed by considering the social, economic and governmental aspects. Detailed information on the focus group interview is given in the following sections. 


\section{On New Media And Surveillance}

According to TDK (Turkish Language Association), the Turkish word medya, which is defined as means of communication or communication mediums, is adapted from the English word 'media'. The word media is the plural form of the Latin word medium meaning means/medium. Psychics are those who communicate with a metaphysical world and think that they are different from other people. The fact that individuals do not usually see the source and that there is no intermediary object or person among the information conveyed by the psychic has made this concept different from what it is. When the media is viewed from this perspective, it is seen that it performs similar works with the psychics. Media provides audiences with the opportunity to communicate in a manner where the source is often unclear, invisible, and no feedback can be provided with incoming messages. In this context, the media, like the psychics, mediates the access to information, and at the same time, with the power to influence, impresses the masses with the information transfers from it. According to Fuchs, media are information and communication technologies, techno-social systems that enable and restrict human activities that create information, where dynamic and transformational processes linking technological structures and human perpetrators with the help of technology are produced, distributed and consumed (Fuchs, 2016). Although the sources mention that the media began to be talked about in the 1920s, the interest in the means of communication is much older. Although the sources mention that the media began to be talked about in the 1920s, the interest in the means of communication is much older. Barbier and Lavenir describe the media as, "all communication systems in a society that provide the ability to fully or partially fulfill the three basic functions of storing, transmitting messages and information remotely and updating cultural and political practices," (Barbier and Lavenir, as cited in Mora, 2008: 5). According to McQuail, the media is a source of power as potential tools of influence, control and innovation in society; it is the source of information and the means of transfer for the work of most social institutions (Türkoğlu, 2010: 70). McLuhan, on the other hand, stated that media is in fact a tool with his 'medium is the message' words and pointed out that the important power is on the media. He explained that the media should draw attention to what and how they say it rather than what it says.

Unlike what was known in the traditional era, the new media brought about a holistic change. The new media, based on computer-based technologies, paved the way for users to create their own tools rather than providing them with a tool. With the new media, the concepts of digitality, interactivity, hypertextiveness and modularity have come to the fore. Since traditional media products transfer themselves to the electronic environment through codes, a transformation called digitalization has taken place. "Digitality is the expression of data according to binary number system. In the digital environment, objects are represented by codes consisting of the numbers zero and one" (Yengin, 2012: 50). In this digital world, products have communicated with their users in a network that is different from the known types of communication. Especially in Web 1.0, the user who cannot intervene in the content is involved in the content with Web 2.0 and a user-based interaction environment is created from an electronic screen. In this interaction environment, users had the opportunity to intervene in the content, wrote comments to the published content and kept the opportunity to change the form according to their wishes. The user, who is passive in the traditional media, has activated this situation with the new media and positioned himself in the middle of the content presented by the media. With the possibility of moving media content from one text to another, the journey between the contents started and this resulted in hyper-textuality. "The audience who gives instant feedback to every message coming from the media thanks to the possibilities of the computer-mediated communication environment, on the one hand, should be described as the consumer but also the producer of the media" (Güngör, 2016:141). While each user creates their own images as a content producer at the moment they are connected, it would be appropriate to say that they, on the other hand, are the consumers of the other content in the new media. In other words, the new media can give the individual both the freedom to produce and the pleasure of consumption from the same screen.

The concept of surveillance is much older than the new media because in the early ages people considered the eye as one of the most important sensory organs and tried to place the eye as a figure in all the works. It was also thought that the eye figures used to be an efficacy against superstitions would be a tool for protection from evil eye. In Egypt, the eye figure placed on top of the pyramids symbolized inequality and hierarchical relations in society. This eye figure, which is frequently used by the rulers of the society, gave the message "I am everywhere and watching you". The governments also carried out surveillance activities in order to show their power and to keep 
individuals under control. "Surveillance function; It is one of the social functions of communication and expresses the collection and dissemination of information about the events taking place both inside and outside a certain society" (Mutlu, 2008:119). Over time, surveillance has been the subject of many theories and books. In George Orwell's 1984 novel, it's been constantly repeated that Big Brother meets with people through tele-screens, people think that they are being watched even in front of the television, and whatever they do, Big Brother is watching them and society is confined to surveillance. This was mainly due to the fact that Foucault replaced Panopticon with his own idea, which could be called a modern prison, based on the idea that the prisoners feared and restrained themselves from a higher authority, which they could not see the source of, but knew that existed. "Panopticon is a machine for separating the pair to see and be seen. Those under surveillance are seen but not able to see" (Foucault, 1992: 252-25). Individuals in the panopticon limit themselves to the fact that they are under surveillance even if they are not supervised, thus experiencing some kind of limitation.

In addition to the conditions of society, the increase in opportunities as time goes on has differentiated the function of surveillance, and instead of the products put forward as a figure, a surveillance system that follows individuals in the digital world like a shadow has entered our lives with the new media. "Together with technology, the more easily monitored, controllable and manageable situation of communities and individuals reinforces the phenomenon of surveillance" (Tingoy, 2009, p.33). In today's surveillance system, individuals, whether they want to or not, fall under some surveillance activities and feel compelled to do so. "The panoptic society, which Bentham dreamed of, Foucault theorized in the academic field, and Orwell called dystopia, became possible with electronic networks" (Dolgun, 2005: 10). As soon as individuals leave their homes, they have agreed to monitor, starting from apartment cameras, the time they leave the house, boarding the bus, which stores they enter in the shopping malls, and how many hours they stay outside. With the development and digitalization of surveillance, individuals transferred their entities to a digital environment and consented to the processing of their personal data with various digital codes and numbers and became the object of surveillance from their home computers to the telephones they carried in their pockets. Surveillance directs and influences individuals and groups by focusing on the social and economic categories of people or on their computers where personal data are collected. "Surveillance is always ambiguous" (Lyon 1994: 219; Newburn and Hayman 2002: 167-168, cited in Lyon 2003: 13). Today's most recent method of surveillance is access to databases containing the information of personal data for various purposes. Biometric, fingerprinting, handprinting, eye scanning, DNA sampling have also been associated with abstract identities and are other applications that increase the speed of surveillance.

While all of this was happening, society had a culture of surveillance. "The phenomenon of surveillance culture has also come to the fore with the 'synopticon' concept developed by Thomas Mathiesen, a Norwegian sociologist. Here, there is a process of surveillance where people sit and watch the lives of others by not being detached from the locality, being drawn to cyber space. Today, with the widespread use of the internet, the transition from synoptic to 'omnipticon' has taken place. There is now a surveillance process in which the majority observes each other. It is seen that people keep each other's lives under surveillance via social sharing networks such as Facebook and Twitter" (Binark, Dikmen, Fidaner et al, 2012: 33). Surveillance is not only limited to social life, but also manifests itself in all practices in individuals' lives. Surveillance makes itself felt in many areas of commerce, health, social and economic.

When the existing forms of surveillance in the digital world are examined, the following table is created in terms of economy, society and state practices. As can be seen in the table, Apple PAY Payment System, credit cards, tokenization, internet banking and virtual piggy bank applications are listed under the economy heading. When the applications in terms of society are considered, the places that are entered by using fingerprints, city surveillance cameras, systems where internet data is recorded and IP numbers of the computer can be seen. Under the title of state practices, there are applications such as e-government application and the storage of fingerprints of citizens. Each application functions as an surveillance mechanism when it is examined in terms of its functioning. 


\begin{tabular}{|c|c|l|}
\hline \multicolumn{3}{|c|}{ SURVEILLANCE METHODS } \\
\hline \multicolumn{1}{|c|}{ ECONOMY } & SOCIETY & \multicolumn{1}{c|}{ STATE } \\
\hline $\begin{array}{l}\text { Apple PAY / BKM Express } \\
\text { Payment System }\end{array}$ & Places entered using fingerprint & $\begin{array}{l}\text { E-Government } \\
\text { application }\end{array}$ \\
\hline Credit cards & $\begin{array}{l}\text { City surveillance } \\
\text { cameras (MOBESE) }\end{array}$ & $\begin{array}{l}\text { Storing fingerprints of } \\
\text { citizens }\end{array}$ \\
\hline Tokenization System & Security cameras & \\
\hline Internet banking & Internet data storage systems & \\
\hline Virtual piggy bank applications & IP numbers of computers & \\
\hline
\end{tabular}

Table 1: Application areas of surveillance in terms of "Economy, Society and State"

When the reflections of this transfer on the economy, society and the state are examined, it is seen that the trade, which was first made by exchanging goods and then formed by purchasing power of money, has transformed into an activity carried out through chip systems with globalization and digitalization. In view of this transformation of trade, many ideas and practices have been put forward. Bill Gates explained that, at this point, capitalism has gone beyond the known meaning and that this new situation is called frictionless capitalism with this words, "The information highway will extend the electronic marketplace and make it the ultimate go-between, the universal middleman. All the goods for sale in the world will be available for you to examine, compare, and, often, customize. Information about venders and their products will be available to any computer connected to the highway. Servers distributed worldwide will accept bids, resolve offers into completed transactions, control authentication and security, and handle all other aspects of the marketplace, including the transfer of funds. This will carry us into a new world of low-friction, low-overhead capitalism, in which market information will be plentiful and transaction costs low" (Davutoğlu, 1999: 176). Accordingly, it is seen that the boundaries of capitalism have expanded and diversified their spheres, and consequently the abandonment of the understanding of industrial era has started. The digital economy also led to the emergence of a system called tokenization. In order to ensure the completion of the shopping and to minimize the return of the products from the basket, payment systems providing tokenization services have started to be established. With this system, users enter their credit card and address information into the system once and they do not need credit card information every time they shop. In this payment system, a token is given in return for credit card information, thus preventing users' personal information from being shared with other sites. In addition, diversification has started in digital payment systems. Apple Pay, BKM Express applications also offer users different options for payment. In Apple Pay and BKM Express, where tokenization system is used, the information of the users is transmitted to the bank and passed to the bank approval and then a number is assigned to the users for their purchases. With these applications, which can also be defined as digital wallets, users can make credit or debit card identifications and pay with their codes during their payment. This system, which saves time, even if it is 3-5 seconds, and saves users from carrying their credit cards with them, shows how much users spend on which website, what time they shop and what they buy, and makes it easier to audit. An example of the activities carried out within the scope of digital surveillance was the cameras placed throughout the country for the purpose of providing security and public order of the state. This system, which provides visual surveillance, is called Close Circuit Television (CCTV) in the world and Mobile Electronic System Integration (MOBESE) or Urban Security and Management System (KGYS) in our country (Derdiman and Tataroglu, 2016: 255). Besides, the fact that various cameras have night vision, the zoom function and the ability to record audio in addition to the image have been used to indicate that another dimension to digital surveillance has been added. In this way, individuals share their data of from where they head away, where they will go, who is with them and how fast they go with the cameras lined up along the way. "With virtual surveillance, electronic language and discourse has started to identify and control people (Gücüyener, 2011: 71-72)." Applications also provide users with the information they need to survive. One of these applications, the E-government portal, which was opened for use in 2008 , is an area where individuals can access their ID numbers and passwords they have received and have the opportunity to monitor their real-life identities on the internet. Many data that citizens do not know that they have been registered from the moment they were born until now are shared with the citizens through the E-government. From a different viewpoint, it is clear that this surveillance tool may also be seen as a model in which "the quality / price performance" criteria are applied, in which citizens are seen as "customers" and public administration activities as "services" (Uckan, 2003: 44-45). Individuals have been able to access a lot of information from their title deed information to when they will retire, from their own debts to criminal records. However, the electronic storage of citizens' fingerprints is another point that encodes individuals into the digital world. Citizens who have strengthened their digital identities with their 
fingerprints have also become easier to follow and identify. Nowadays, many companies make their own records by asking their customers for their ID number during their sales transactions or for membership cards, discount cards or similar applications. This becomes even more important when certain services are purchased. "In addition to commercial registrants, many institutions and organizations (political parties, NGOs, municipalities, universities, pharmacies, hospitals, shops) also require identification numbers for many transactions" (Binark et al., 2012: 85). Therefore, it can be said that digital identities have a great place in the life of individuals. When these surveillance practices, which are sometimes informed or sometimes unannounced, are examined, it is seen that their numbers are very high. It can be said that surveillance is found in many places in our lives when individuals are set out to maintain their virtual identities in an environment where their data is continuously recorded on the internet and being watched with cameras from the moment they leave their homes until they come to their homes.

\section{Research Methodology}

In this study, focus group study method was used in addition to literature scanning. The main starting point is the focus group interviews, which are basic psychology, social psychology and communication theories, and qualitative data collection method which is frequently used in action research. This method, which forms the basis for one-on-one interviews and surveys in the social sciences, is in fact one of the most systematic data collection methods (Kitzinger, 1995). Focus group interviews have an important function in qualitative data collection. Qualitative research designs and methods focused on a defined topic and group interviews discussion technique can be expressed as focus group interview (Yıldırım \& Şimşek, 2008). Although there are different views on the number of participants, these studies usually require a small number of participants. This number usually varies between 4 and 10 people. Based on these points, the study sample consisted of 10 people aged between 18-23. All participants are educated in higher education institutions. The questions asked to the focus group participants determined by the conformity sampling method (Aziz, 2014) were pretested on a group of 8 people before the study. The interview took place on 2 April 2019 and the meeting room was prepared according to the U-table layout before the participants came to the hall. During the interview, the second author moderated the group and recorded digital audio in the hall. The voice recording of the focus group study took a total of 1 hour and 24 minutes. Demographic details of the group are given in the research findings section. The questions were asked to the group by considering the social, economic and state dimension of the concept of surveillance, and the sound recording taken during the study was then transferred to frequency tables and also the opinions of the participants were included under each table. The aim of the research is to reveal what the participants think about the concept of digital surveillance on the new media axis.

\section{Research Findings}

Of the 10 focus group participants aged 18-23, 6 are male and 4 are female participants. The cities of the participants are Çanakkale, Ankara, Balıkesir, Batman, Van, Gaziantep, İstanbul and Kütahya. All participants are students of higher education institutions. The demographic table of the participants is as follows.

\begin{tabular}{llll} 
Code & Gender & Age & $\begin{array}{l}\text { Registered } \\
\text { Province }\end{array}$ \\
\hline P1 & M & 22 & Canakkale \\
\hline P2 & F & 23 & Ankara \\
\hline P3 & F & 18 & Balikesir \\
\hline P4 & M & 21 & Canakkale \\
\hline P5 & M & 19 & Kutahya \\
\hline P6 & F & 19 & Canakkale \\
\hline P7 & M & 23 & Konya \\
\hline P8 & F & 21 & Gaziantep \\
\hline P9 & M & 22 & Van \\
\hline P10 & M & 21 & Istanbul \\
\hline
\end{tabular}

Table 1: Demographic definitions of the group in which the focus group study was conducted 
In the following section, the data obtained during the focus group interview are first presented with tables. At the bottom of each table, the participants' discourses on the focus group question are compiled.

The participants were asked whether they had given fingerprints in hospitals or police departments before and what they thought about these practices. Nine of the participants stated that they did not mind taking fingerprints and one of the participants stated that they were uncomfortable with the fingerprint. The statements of some of the participants are given at the bottom of the table.

\begin{tabular}{ccc}
\hline QUESTION 1 & Frequency & Percent (\%) \\
\hline $\begin{array}{c}\text { I don't mind if government agencies get my } \\
\text { I find it inconvenient that government }\end{array}$ & 9 & 90 \\
fingerprints. & 1 & 10 \\
organs get my fingerprint. & & \\
\hline
\end{tabular}

Table 2: Focus group first question

The P1 coded participant stated that he was uncomfortable with the state registering himself with his fingerprint, saying, "I think it's a bad thing that fingerprints are taken since it will appear legally in all transactions."

On the other hand, it was recorded that the P2 coded participant said that she saved time thanks to the fingerprint application and that this was a convenience in her life, saying, "I gave my fingerprint in a private hospital in Besiktaş, İstanbul. Now every time I go, they find my ID with my fingerprint, which I think is very convenient."

The P3 coded participant expressed her opinion saying, "As an example, the phone we use now also opens itself with the fingerprint application. So this is the current technology, the eye recognition feature will be fully used soon, this is a convenience. The state can record us under any circumstance, I think the important thing is not to use these records for bad purposes."

A significant number of the participants stated that they were not disturbed by the government's fingerprint applications. From this point of view, it should be noted that the participants also state that the government provides convenience with fingerprint applications. The focus group participants are satisfied with the government's fingerprint application.

The participants were asked what they think about the MOBESE systems established by the state in order to provide security and public service. Ten of the participants stated that they were satisfied with this situation and did not feel uncomfortable about being recorded.

\begin{tabular}{ccc}
\hline QUESTION 2 & Frequency & Percent (\%) \\
\hline $\begin{array}{c}\text { I think MOBESE systems are beneficial to } \\
\text { our lives. }\end{array}$ & 10 & 100 \\
I'm annoyed at being constantly watched & 0 & 0 \\
with MOBESE. & & \\
\hline
\end{tabular}

Table 3: Focus group second question

The P4 coded participant thought that MOBESE systems were beneficial and stated, "I think MOBESE systems are very useful. Because supposing that someone hit me, I can use the security footage while I claim my rights."

It was recorded that the P7 coded participant mentioned about the limitation of the areas where the security cameras could record with these words, "I think MOBESE cameras are beneficial as long as they respect for my private life."

It was noted that the participants stated that they were generally satisfied with the government's MOBESE applications and that they were beneficial in terms of security. 
As the third question, participants were asked what they think about e-government applications. While 3 of the participants were disturbed by the fact that every information was recorded due to the application, 7 of them stated that they were pleased with the use of e-government and that their records were kept and even they thought that e-government applications provided an advantage.

\begin{tabular}{ccc}
\hline QUESTION 3 & Frequency & Percent (\%) \\
\hline I think that e-government application is & 8 & 80 \\
$\begin{array}{c}\text { Keneficial for our lives. } \\
\text { Keeping records of me in the e-government }\end{array}$ & 2 & 20 \\
application annoys me. & & \\
\hline
\end{tabular}

\section{Table 4: Focus group third question}

The P8 coded participant stated that she thought the application was beneficial to her life, saying, "Compared to previous periods, like 10 years ago, doctors were telling us to bring our X-rays. Now everything's on their screens. This is a great convenience."

The P10 coded participant, from a critical point of view, said, "I think it's harmful because the scammers have a new opportunity. They can defraud you when your information is reached, but I did not fall into this situation at the last moment. So I think it's a disadvantage because I think it can be deciphered. I think there is a disadvantage in everything that provides convenience." He stated that he believes that e-government applications can turn into disadvantages.

Participants' perspectives on e-government applications are generally positive. Two of the participants expressed concern about the damage that could arise if the information in e-government applications were reached by other people.

Participants are asked the following questions: "Do you know that your searches as an Internet user are recorded or what music you're listening to or which movie you're downloading is known or recorded? What do you think of this?" 7 of the participants stated that there was no problem in recording the internet searches or activities and 3 of them stated that they were uncomfortable with the recording.

\begin{tabular}{ccc}
\hline QUESTION 4 & Frequency & Percent (\%) \\
\hline $\begin{array}{c}\text { The fact that the activities I perform online } \\
\text { are recorded doesn't bother me. } \\
\text { The fact that the activities I perform online }\end{array}$ & 7 & 70 \\
are recorded bothers me. & 3 & 30 \\
\hline
\end{tabular}

Table 5: Focus group fourth question

The P6 coded participant expressed her discomfort with being recorded and said, "There's nothing called private life now. Everyone's private lives are particular to them, but not anymore." The P5 coded participant, with a different point of view, stated that he was not disturbed by the recording of his activities on the internet, saying, "For example, when I go somewhere and don't share it, it's like I'm doing something secret. I even share stories to show that I'm not doing anything secretly. Therefore, I am recording myself anyway, so it does not bother me to be recorded."The participants stated that they were not generally disturbed by the registration of internet activities. They also stated that they did not conduct any confidential transactions on the Internet and therefore they did not mind if they were recorded by any authority. On the other hand, it is necessary to mention the presence of participants who stated that they were disturbed by the recording of their private lives. Participants were asked whether they viewed increased traceability over IP addresses as an advantage or a disadvantage. All participants considered the traceability of IP addresses as an advantage. Discourses of the participants are given at the bottom of the table.

\begin{tabular}{ccc}
\hline QUESTION 5 & Frequency & Percent (\%) \\
\hline The easy tracking of IP addresses is an & 10 & 0 \\
advantage. \\
$\begin{array}{c}\text { The easy tracking of IP addresses is a } \\
\text { disadvantage. }\end{array}$
\end{tabular}

Table 6: Focus group fifth question 
The P3 coded participant stated that it is an advantage to be able to track IP addresses, saying, "I think they should be trackable. Thus, fake accounts can be revealed."

The P9 coded participant thought that it is useful to have easy tracking over IPs and said, "It is a good thing that IP addresses can be tracked and monitored."

Participants don't view the traceability of IP addresses as a means of surveillance, in other words, they think that this is an advantage.

Participants were asked what they think of being traceable to banks as they use their bank cards. While 8 of the participants did not see any harm in this, 2 of them stated that they were uncomfortable that their every purchase are recorded.

\begin{tabular}{lcc}
\hline QUESTION 6 & Frequency & Percent (\%) \\
\hline I think it's okay to be recorded with our bank & 8 & 80 \\
cards. & & 20 \\
I think it's not okay to be recorded with our & 2 & \\
bank cards. & &
\end{tabular}

Table 7: Focus group sixth question

The P8 coded participant expressed her discomfort saying, "I don't think it should be recorded. It's pointless."

On the other hand, the P6 coded participant expressed her opinion as she did not feel any disturbance from the records made by the banks, saying, "I don't think it matters. Every person goes to a cafe, every person goes shopping. So?"

The P3 coded participant said, "Let's say there are large inflows of money, for example, if it is irregular process, it'll be known immediately, or let's say you have rent income, the state can follow up and get the tax from you. I think the fact that the records are being kept is an advantage." It was recorded that the participants were not disturbed by the records kept on their bank cards in general.

Participants were asked what they think of uploading their identification numbers to the system when shopping online. While 9 of the participants did not mind that they recorded their identification numbers, only one participant expressed his discomfort about it.

\begin{tabular}{ccc}
\hline QUESTION 7 & Frequency & Percent (\%) \\
\hline $\begin{array}{c}\text { I'm not content with giving my identification } \\
\text { number when shopping. } \\
\begin{array}{c}\text { I don't mind giving my identification number } \\
\text { when shopping. }\end{array}\end{array}$ & 1 & 10 \\
\hline
\end{tabular}

\section{Table 8: Focus group seventh question}

The participant P6 stated that she was not bothered to give her identification number when shopping and said, "I don't mind giving my ID number to the sites I trust." On the other hand, The P4 coded participant expressed his discomfort, saying, "The ID number is important, they can even set up a company with your ID number."

Participants state that they do not feel uncomfortable using their identity number in ecommerce applications.

\section{Conclusion}

Although a significant part of the new media theories record that digital developments increase the concept of surveillance and spread to every area of life and criticize a significant part of the developments, users are pleased with the applications that make life easier. The data of this study is carried out on a focus group of 10 people ( 6 male and 4 female) aging between 18-23. The focus group studies aim at revealing the opinions and thoughts of the group participants rather than aiming 
to reach generalizations. In this context, when the views of the participants are elaborated, it is possible to say that each participant is not critical of the concept of surveillance emerging with new media technologies, albeit with different ways of thinking. On the other hand, it should be noted that while the participants affirm the concept of surveillance, they also want their boundaries to be drawn. As an example, participants think that it is convenient to give their ID numbers to the e-commerce site, but they can only apply it to the sites they trust. Another new media user states that MOBESE cameras meet the security needs and must be in their lives, while at the same time, he will not be pleased to be recorded in his private life. In short, while participants are satisfied with the world of surveillance of new media technologies, they also think that the limits of surveillance should be drawn relatively. However, it should be noted at this point that each participant's "limitation" approach differs from each other.

Although the data obtained as a result of the focus group study shows that the users are satisfied with the developments, it is a fact that digital surveillance surrounds our lives with many applications. Within the scope of surveillance, recording the time when individuals make online searches, how long they stay on the websites they have entered as a result of the search, and what they download or save as a result of these search results, and where they are when they make the search has become the cornerstone of digital surveillance. From this point of view, the institution / person / organization conducting the surveillance has the ability to take all the data belonging to the individual they observe and use them in their own way. In this plane, which is called a kind of virtual panopticon, individuals know that every movement they make on the internet is recorded in some way, but they do not know who does this and for what purpose. In such an environment, individuals pay more attention to their movements in the digital environment and enter into a state of self-control. Individuals have withdrawn themselves thinking that they will face the results of this if they do something bad and have tried to use their identities in the virtual environment more simply. This is because individuals who know that they are not being monitored only by cameras, approach everything they hold as a potential surveillance tool. The closure of computer cameras with tape and the unreal information given when subscribing to any site has become a set of actions internalized by individuals to escape surveillance.

Digital developments surrounding the world have enabled the society to be observed at the same speed. Although these rapid developments seem to protect the user with the consent of the user, they have initiated a digital surveillance. In this context, while the citizen can be recorded at every step, every movement, every shopping or every transaction, his traceability increases and on the other hand he feels protected by these surveillance techniques. At this point, it should be said that digital surveillance will show itself more as new media applications increase. The user will knowingly continue to be recorded, in other words, to use new media applications. In addition, the so-called cookie software in the Internet browser allows users to control their virtual identity from anywhere. People voluntarily share information such as what they eat and drink in the cafes they go to, who they sit at the same table with, what work they do, where and with whom they live and in doing so, they make a contribution to this by accepting surveillance. In addition, information such as which sites he entered and what time, what he looked at, which photographs he searched are added on the person's virtual identities on the Internet. This virtual identity, combined with the "personalization" policy of the internet, leads to the creation of a world that is specific to the individual. The products that will attract the attention of the individual in this world are offered to him and individuals can make friends suitable for all kinds of political, economic and social views of his. Initially beautiful and thought to provide convenience to individuals, this idea is essentially equivalent to closing a person in a mirrored room. In this world where the same things are constantly spoken, the same things are hated or loved and there is a common single voice, the individual comes to the point of having difficulty in accepting it when he encounters other thoughts outside his own thought.

\section{References}

[1] Arslantaş Toktaş, S., Binark, M., Dikmen, E.Ş., Fidaner Barış, I., Küzeci, E., Özaygen, A (2012). Türkiye'de Dijital Gözetim T.C. Kimlik Numarasından E-Kimlik Kartlarına Yurttaşın Sayısal Bedenlenişi, Alternatif Bilişim Derneği: İstanbul

[2] Aziz, A. (2014). "Sosyal Bilimlerde Araştırma Yöntemleri ve Teknikleri”, Ankara: Nobel.

[3] Cover, R. (2016). Digital Identities, Elsevier: USA.

[4] Davutoğlu, E. \& Erdal A. (1999). "Önümüzdeki Yol", Arkadaş Yayınevi: Ankara. 
[5] Derdiman, R. Cengiz, Tataroğlu, Nihal (2016). "Devlet Gözetimi ile İnsan Haklarının Uyumlaştırılması Sorunu ve Çözüm Önerileri”, İnönü Üniversitesi Hukuk Fakültesi Dergisi, 7 (1), 247-294.

[6] Dolgun, U. (2005). "Enformasyon Toplumundan Gözetim Toplumuna", Ekin Kitabevi:Bursa

[7] Foucault, M. (1992a). "The Birth of the Prison" (Trans. M. A. Kılıçbay): Ankara: İmge.

[8] Fuchs, C. (2016), "Social Media: A Critical Introduction", Nota Bene Publishing, Ankara.

[9] Gücüyener, M. (2011). "Anoptikonik Gözetimden Synoptisizme Gözetim Toplumu", Yayınlanmış Yüksek Lisans Tezi, Afyon Kocatepe Üniversitesi Sosyal Bilimler Enstitüsü, Afyonkarahisar

[10] Güngör, N. (2016). "İletişim, Kuramlar, Yaklaşımlar", Ankara: Siyasal Yayınları

[11] Kitzinger, J. (1995). "Qualitative Research: Introducing Focus Groups", British Medical Journal, 311, 299-302.

[12] Lyon, D. (2003). "Surveillance as Social Sorting", Routledge: New York.

[13] McLuhan, M. (2001). "Understanding Media: The Extensions of Man", Cambridge: The MIT Press, Washington.

[14] Mora, N. (2008), "Medya, Toplum ve Haber Kaynağı Olarak Sembolik Seçkinler", Uluslararası Insan Bilimleri Dergisi 5(1)

[15] Mutlu, E. (2008), "İletişim Sözlüğü", Ayraç Publishing: Ankara.

[16] Simon, P. S., Sanz, E., Prato, Giuditta (2014). "Digital Media Worlds", Palgrave Macmillan: London.

[17] Tıngöy, Ö. (2009). "Bilişim Çağında Etik". İstanbul: Avcıol Basım Yayın.

[18] Türkoğlu, N. (2010). "Toplumsal İletişim". İstanbul: Urban.

[19] Uçkan, Ö. (2003). E-Demokrasi ve Türkiye, Kamu Yönetiminin Yeniden Yapılanması İçin Strateji ve Politikalar-I, Literatür Yayıncılık: İstanbul.

[20] Yengin, D. (2012). "Yeni Medya ve Dokunmatik Toplum" Derin Yayınları: İstanbul.

[21] Yıldırım, A. \& Şimşek, H. (2008). Sosyal Bilimlerde Nitel Araştırma Yöntemleri, Ankara, Seçkin Publishing. 